\title{
A PRODUÇÃO DE CASTANHA DE CAJU E A DINÂMICA SOCIOESPACIAL DO MUNICÍPIO DE CARAÚBAS - RN
}

\author{
L. V. FERNANDES* \\ Instituto Federal de Educação, Ciência e Tecnologia do Rio Grande do Norte \\ larygeo@yahoo.com.br*
}

Artigo submetido em outubro/2015 e aceito em novembro/2015

DOI: $10.15628 /$ geoconexoes .2015 .3693

\section{RESUMO}

A cultura do cajueiro começou a se desenvolver na zona rural do município de Caraúbas - RN na década de 1960. Observando a alta produção de caju, um grupo de empresários da cidade de Mossoró - RN instalou uma fábrica de beneficiamento da castanha de caju na zona urbana de Caraúbas denominada de Ademos Ferreira da Silva - Indústria, Comércio e Exportação (AFICEL). Após a instalação da unidade industrial, a vida urbana de Caraúbas foi dinamizada elevando-se o número de empregos gerados e a consequente indução do incremento na oferta dos serviços na cidade, como também, permitiu o surgimento de vários empreendimentos comerciais ea implantação da fei ra de confecção. Desse modo, o presente artigo tem como objetivo analisar a dinâmica socioes pacial de Caraúbas RN decorrente da atividade de produção de castanha de caju, no período compreendido entre os anos de 1980 e 2009. Para alcançarmos tal objetivo, fizemos uso de pesquisa bibliográfica, observações diretas na área de estudo, além da aplicação de formulários junto aos administradores da indústria de beneficiamento da castanha de caju, e aos agricultores que fornecem a matéria-prima. Com o estudo observou-se que a cajucultura e a fábrica de beneficiamento de castanha de caju contribuem significa tivamente para a atual dinâmica socioespacial do município de Caraúbas - RN

PALAVRAS-CHAVE: Castanha de caju, Caraúbas, Dinâmica Socioespacial.

\section{A CASHEW NUT PRODUCTION AND DYNAMIC SOCIALSPACE IN THE CARNAÚBA- RN CITY}

\begin{abstract}
The cultivation of cashew began to develop in the rural municipality of Caraúbas - RN in the 1960s. Noting the high cashew production, a group of businessmen from the city of Mossoró - RN installed a factory processing of cashew nuts in urban Caraúbas called Ademos Ferrei ra da Silva - Industry, Commerce and Export (AFICEL). After installation of the plant, urban life Caraúbas was boosted by raising the number of jobs created and the consequent induction of the increase in the supply of services in the city, but also allowed the emergence of several business ventures and the establishment of fair cooking. Thus, this
\end{abstract}

article aims to analyze the dynamics of socio Caraúbas RN activity resulting from production of cashew nuts in the period between 1980 and 2009. To achieve this goal, we made use of literature, direct observations in the study area, in addition to the application formalong with the administrators of processing industry of cashew nuts, and farmers that provide the raw material. In the study it was observed that the cashew culture and processing plant cashew contribute significantly to the current dynamics of the socio municipality Caraúbas - RN.

KEYWORDS: Cashew nuts. Caraúbas; SocioSpatial Dynamics. 


\section{INTRODUÇÃO}

O município de Caraúbas situa-se na mesorregião Oeste Potiguar e, mais precisamente, na microrregião da Chapada do Apodi, limitando-se ao Norte com os municípios de Governador DixSept-Rosado e Felipe Guerra, ao Sul com Janduís, Patu e Olho D’Água dos Borges; ao Leste com Campo Grande e Upanema e a Oeste com Apodi. Do ponto de vista geográfico, Caraúbas se localiza na latitude: $5^{\circ} 47^{\prime} 33^{\prime \prime}$ Sul e longitude: 37 33' 24" Oeste, distando - se $309 \mathrm{Km}$ da capital potiguar, Natal. (Mapa 01)

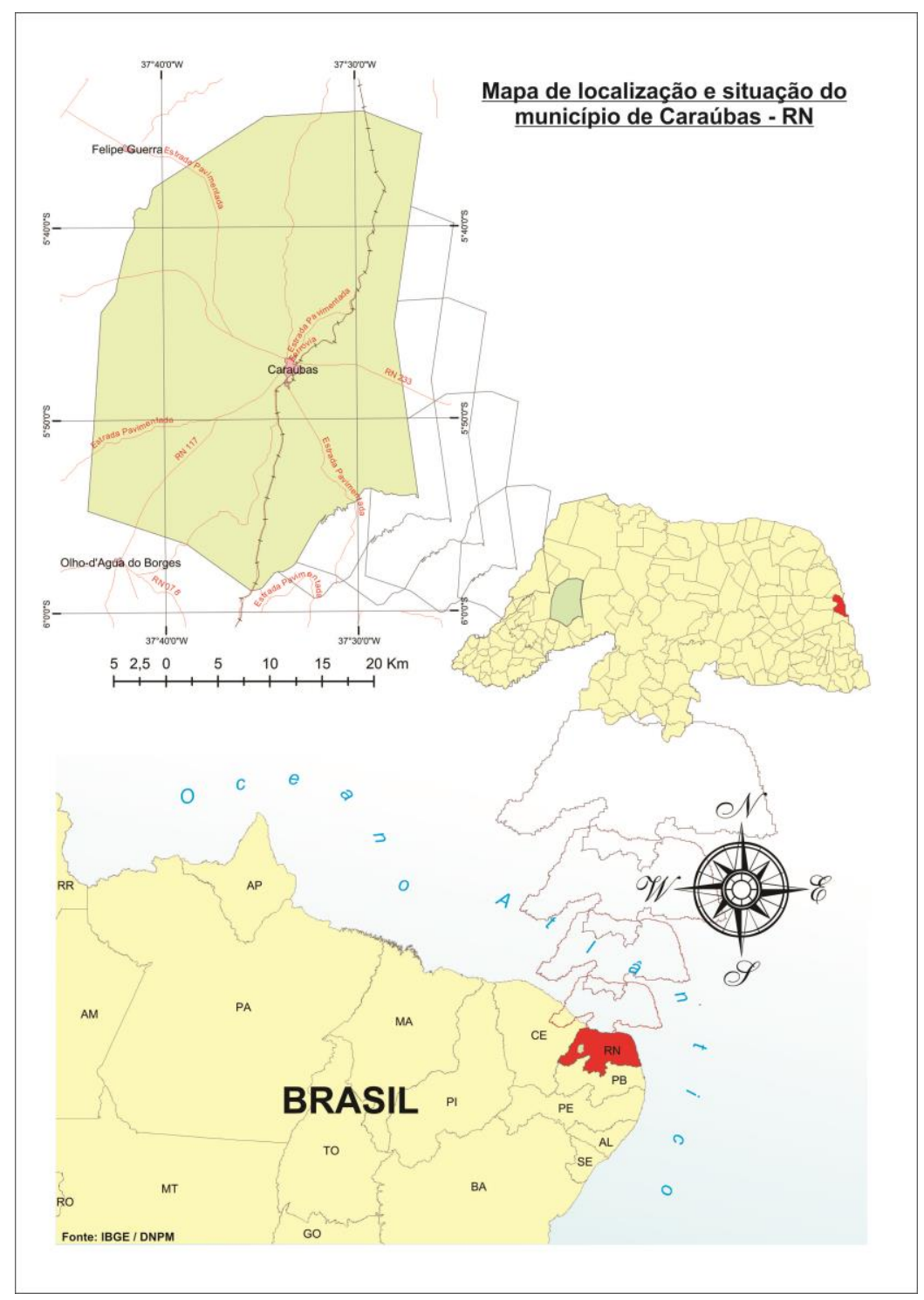

Mapa 01 - Mapa de Localização e situação do município de Caraúbas - RN. Adaptado por FARIAS, 2010.

A terra das caraubeiras, como é comumente denominado pelos moradores mais antigos, possui uma área territorial de $1.099,9 \mathrm{~km}^{2}$ que equivalente a $2,06 \%$ da superfície estadual e a altitude da sede é de 144 metros. De acordo com os dados do Instituto Brasileiro de Geografia e Estatística (IBGE, 2010), Caraúbas possui uma população de 19.576 habitantes, dos quais, 13.704 habitantes ocupam o espaço urbano e, 5.872, a zona rural. 
Seguindo o processo de expansão da pecuária e ocupação das áreas interioranas do Nordeste, Caraúbas inicia o seu processo de formação socioespacial e desde que foi elevada a categoria de município, dispunha somente da agricultura e da pecuária como atividades econômicas produtivas do espaço caraubense.

No final da década de 1920, o município passa a viver uma nova dinâmica econômica em seu espaço, com a instalação tanto na zona urbana, como na rural de estações da linha férrea que ligava a cidade de Mossoró a Sousa na Paraíba. A partir desse evento, Caraúbas passa a ser considerado um entreposto comercial. Na década de 1940, com a expansão da cotonicultura, o município passa a vivenciar outro crescimento econômico, trata-se da instalação de uma usina de beneficiamento do algodão, a qual promoveu uma maior integração entre a zona rural e a zona urbana. Nos anos 70, a cultura do algodão entra em decadência, e dez anos mais tarde, a linha férrea é desativada, devido à construção da rodovia RN -117. É nesse período que inicia a prática de uma nova atividade econômica no solo caraubense: a cajucultura.

A produção de caju no município teve início em 1964, mas somente em 1984 que a atividade alavancou, pois foi nesse período que foi instalada em Caraúbas uma fábrica de beneficiamento da castanha de caju, utilizando a infra-estrutura e o prédio deixados pela antiga usina de beneficiamento do algodão.

Essa fábrica, denominada Ademos Ferreira A Ferreira da Silva - Indústria, Comércio e Exportação - S.A - AFICEL provocou uma dinâmica socioespacial no município, pois proporcionou o aumento de empregos da cidade, já que funcionava com 700 funcionários, todos de Caraúbas. Novos estabelecimentos comerciais surgiram, foi nesse período que a população urbana ultrapassou a população rural, fruto da intensificação do êxodo rural e houve uma expansão urbana no bairro cuja fábrica estava instalada.

Do exposto, percebemos o quão importante é a produção de castanha de caju para o município. E a partir dessa constatação, buscamos, nesse trabalho, analisar a dinâmica socioespacial de Caraúbas - RN decorrente da atividade de produção de castanha de caju, no período compreendido entre os anos de 1980 e 2009.

Para alcançarmos tal objetivo, utilizamos pesquisa bibliográfica, observações diretas na área de estudo sendo acompanhadas por registros fotográficos, além da aplicação de formulários com perguntas abertas e fechadas junto aos administradores da indústria de beneficiamento da castanha de caju, e aos agricultores que fornecem a matéria-prima. Também realizamos entrevistas com empresários, comerciantes e moradores do município em estudo.

Dessa forma, o presente artigo está dividido em três partes. A primeira intitulada "Um olhar sobre a produção do espaço" traz, de forma breve, uma abordagem teórica a respeito da produção do espaço. Em seguida, ainda nessa parte do trabalho, tratamos sobre como se deu o processo de ocupação e produção do espaço de Caraúbas. A segunda parte denominada "O desenvolvimento da cajucultura em Caraúbas" fala sobre como essa atividade se desenvolve no espaço caraubense. Por fim, tratamos sobre a atual dinâmica socioespacial e econômica de Caraúbas demonstrando o funcionamento do comércio caraubense, a expansão urbana da cidade, o fenômeno do êxodo rural entre outros aspectos.

Com o desenvolvimento do trabalho, foi possível, afirmar que a dinâmica socioespacial e econômica do município de Caraúbas está intimamente ligada à produção de castanha de caju. 


\section{UM OLHAR SOBRE A PRODUÇÃO DO ESPAÇO}

A compreensão acerca da dinâmica socioes pacial do município de Caraúbas - RN, enquanto fio condutor dessa pesquisa é um exercício que nos remete a discussão sobre elementos que fazem parte do entendimento de tal objeto. Nesse panorama, o conceito de espaço geográfico emerge como arcabouço teórico para que possamos compreender como ele é produzido e reproduzido.

De acordo com Lefebvre (2006, p. 7) o espaço geográfico "reúne o mental, o cultural, o social e o histórico". Nesta concepção, o espaço não pode ser considerado como mero palco de acontecimentos, ele é condição para que determinados tipos de relação se estabel eçam. Desse modo, há uma ligação entre o espaço e as relações sociais, uma é condição de existência para o outro, ou seja, o espaço geográfico possui um viés social, visto que "a organização e o sentido do espaço são produto da translação, da transformação e da experiência social” (SOJA, 1993, p. 103).

Nesse contexto, o espaço não pode ser concebido como vazio ou passivo, ele intervém na própria produção através dos meios de transportes, dos fluxos de matérias-primas e de energias (Lefebvre, 2006). Assim, a produção do espaço geográfico consiste em uma prática social, em que na medida em que a sociedade produz os meios vitais para a reprodução de suas vidas, estão produzindo espaço. Corroborando com esse pensamento, Carlos (1994, p. 22) afirma que:

Os homens, ao produzirem seus bens materiais e se reproduzindo, como espécie produz o espaço geográfico. Entretanto, dependendo do momento histórico o fazem de modo específico, diferenciando de acordo com o estágio de desenvolvimento das forças produtivas. $O$ espaço passa a ser produzido em função do processo produtivo geral da sociedade.

Com base no que diz a autora, verificamos que o espaço é um produto da história fundamentado nas relações entre os homens e a natureza em um determinado momento histórico.

A partir desse momento, surge a ideia de espaço produzido pelo trabalho da sociedade, ou seja, a indissociabilidade entre o espaço e a sociedade. Desse modo, e conforme nos esclarece Carlos (2001), o espaço é condição, meio e produto da sociedade. O espaço é produto porque ele é produzido de acordo com as relações sociais estabelecidas no lugar; da mesma forma, o espaço é condição para que determinadas relações sociais se estabeleçam. Em outras palavras, é continuamente produzido a partir das atividades humanas quem lhe dá sentido e intencionalidade.

A cidade é que fornece todas as condições para a (re) produção do espaço, ela é tida como o lócus da concentração de meios de produção, como também de pessoas. Em outras palavras, a cidade é o lugar onde ocorre a divisão social do trabalho e está em permanente construção em decorrência das exigências dos atores que mencionamos (Carlos, 2004). Da mesma forma, ela ganha importância quando passa a reunir condições necessárias ao desenvolvimento do capitalismo.

Assim, a abordagem teórica realizada até esse momento foi necessária para que possamos compreender como se deu o processo de ocupação e de produção do espaço do município em estudo: Caraúbas - RN. 


\subsection{O processo de ocupação e produção do espaço de Caraúbas - RN.}

A ocupação do sertão do Rio Grande do Norte se deu a partir da pecuária, uma vez que essa atividade ficou impossibilitada de ser desenvolvida nas áreas litorâneas, acarretando o deslocamento do gado para o interior, juntamente com o homem. A partir daí as primeiras fazendas de gado são instaladas, levando em consideração a presença de águas: rios, riachos, açudes e poços que se formavam em meandros dos rios intermitentes. A pecuária nasce sendo subsidiaria aos canaviais, uma vez que "[...] produziam animais para o trabalho nos engenhos, carne e couro para as áreas açucareiras de Pernambuco, e, posteriormente, algodão para o mercado internacional" (FELIPE, 1988, p. 35).

A partir da pecuária foram surgindo algumas povoações no Rio Grande do Norte. Essas povoações eram lugares para o pouso dos vaqueiros e serviam de currais para a alimentação do gado. Nesse contexto, os "caminhos do gado" promoveram uma integração territorial entre o sertão e o litoral; contribuindo, assim, com a ocupação das áreas mais interiores do Nordeste e surgindo algumas cidades no RN como Currais Novos, Caicó e Pau dos Ferros. Portanto, a pecuária exerceu um papel importante na ocupação e povoamento do sertão e de terras do agreste norteriograndense. Como nos aponta Andrade (1988, p. 190):

[...] foi à pecuária quem conquistou para o Nordeste a maior porção de área territorial. Complementou a área úmida agrícola com uma atividade econômica indispensável ao desenvolvimento da agroindústria do açúcar e ao abastecimento das cidades nascentes.

É nesse contexto de expansão da pecuária e ocupação das áreas interioranas do Nordeste e em especial, da exploração e povoamento do interior da então Capitania do Rio Grande, que a cidade de Caraúbas inicia seu processo de formação socioespacial.

Caraúbas nasce a partir da construção da Capela de São Sebastião; templo religioso edificado por um fazendeiro local em decorrência de uma promessa realizada. A cidade cresceue se desenvolveu em torno dessa capela e a partir daí começaram a surgir às primeiras edificações que posteriormente contribuiriam para a mudança na paisagem física do local de rural para uma paisagem urbana.

Desde a sua elevação enquanto município em 1868, Caraúbas tinha somente a agricultura e a pecuária como atividades econômicas produtivas do espaço caraubense. Atividades voltadas somente para a subsistência da população do município.

Somente a partir do ano de 1929, Caraúbas passa a ter um crescimento econômico considerável, uma vez que a estrada de ferro da Rede Ferroviária do Nordeste, antiga Estrada de Ferro Mossoró - Sousa no Estado da Paraíba possuía um percurso de $55 \mathrm{~km}$ dentro do município e mantinha uma estação na zona urbana da cidade e mais duas estações na zona rural. Com a estação ferroviária observou-se um surto no comércio caraubense, já que os produtos trazidos pelo trem eram vendidos em Caraúbas, o que fez surgir novos mercados no município.

Além da linha férrea, outro fator que dinamizou o espaço rural e urbano de Caraúbas foi à expansão da produção algodoeira no município, principalmente após 1940 devido à instalação, na zona urbana caraubense, de uma usina de beneficiamento e preparação do algodão que abastecia a Microrregião Oeste Potiguar e alguns Estados vizinhos como o Ceará. 
O algodão contribuiu para fomentar a dinâmica econômica, política e social de Caraúbas principalmente nas décadas de 1950, 1960 e 1970. Mesmo sendo produzido na zona rural, o centro do município em estudo, passou a vivenciar melhorias em sua infraestrutura urbana. Na década de 1970, a economia algodoeira entra em crise associada a fatores tecnológicos e ao surgimento de pragas, principalmente a do bicudo.

A decadência dessa importante atividade atinge todas as áreas cultivadas de algodão, inclusive Caraúbas ocasionando assim o êxodo rural e promovendo o crescimento das cidades emergindo sérios problemas, uma vez que as cidades não estavam preparadas em termos de infraestrutura para receber tal contingente.

Dez anos após a decadência do algodão, em 1980, a linha férrea que passava por Caraúbas também entrou em decadência devido à construção da rodovia $R N$ - 117, sendo totalmente desativada em 1991. Apesar desses dois lamentáveis eventos, instalou-se na cidade, em 1981, uma fábrica de beneficiamento de castanha de caju. Esse empreendimento denominado Ademos Ferreira da Silva - Indústria, Comércio e Exportação (AFICEL) formada por empresários mossoroenses.

A vida urbana de Caraúbas foi dinamizada após a instalação da indústria de beneficiamento da castanha de caju. A partir dessa produção industrial elevou-se número de empregos gerados e a conseqüente indução do incremento na oferta dos serviços na cidade, com destaque para a ampliação da feira da cidade realizada aos sábados, com implantação da feira de confecção nos dias de pagamento da referida fábrica e o surgimento de vários empreendimentos comerciais. Nesse período (década de 1980) a cidade de Caraúbas vivencia uma transformação no seu perfil urbano, pois é exatamente com os reflexos dessa conjuntura econômica que o município passa continuamente a ter o aumento total de população residente na cidade comparado a população rural.

Dessa forma, fica perceptível a importância que as agroindústrias (a de algodão e de castanha de caju) desempenharam e desempenham na produção do espaço urbano de Caraúbas. Contudo, apesar de serem atividades localizadas no urbano, apresentam estreitas ligações com as atividades desenvolvidas pelo espaço rural do município. Tendo em vista que essas atividades propiciam a dinâmica tanto do urbano tendo em vista, o fluxo de pessoas, o comércio e os serviços que a presença das fábricas implementam na cidade; como também do rural com a produção de matérias-primas.

A atual dinâmica socioespacial do município de Caraúbas é decorrente das atividades ligadas à agropecuária, a industrialização da castanha de caju e ao setor terciário, o que abrange o setor de comércio e serviços. Entretanto, a produção de castanha de caju se destaca como sendo uma das principais atividades econômicas do município. Dessa maneira, no próximo tópico destacaremos como ocorreu o desenvolvimento da cajucultura no município e a importância da agroindústria de beneficiamento da castanha de caju para a dinâmica socioespacial de Caraúbas. 


\section{O DESENVOLVIMENTO DA CAJUCULTURA EM CARAÚBAS}

A cultura do cajueiro começou a se desenvolver em Caraúbas na década de 1960, mais precisamente no ano de 1962 na comunidade rural de Mirandas. De acordo com as entrevistas realizadas em janeiro de 2010, os agricultores dessa localidade nos informou que a produção do caju começou sem "compromisso", era somente para a subsistência da família e o que sobrava era vendida nos dias de feira, como forma de complementar a renda familiar.

Observando a produção de caju no município, um grupo de empresários mossoroenses instalou uma fábrica de beneficiamento da castanha de caju, mais precisamente no bairro Leandro Bezerra (mapa 02) utilizando a infraestrutura deixada pela antiga usina de beneficiamento de algodão. Dessa forma, constituída em 1981, a AFICEL entrou em funcionamento ativo no ano de 1984. De início, a fábrica empregava 100 operários, mas com o passar dos anos, a demanda da produção foi aumentando, propiciando um aumento significativo no contingente de trabalhadores. Assim no período de 1991 a 1993 a fábrica já contava com 700 trabalhadores em suas dependências.

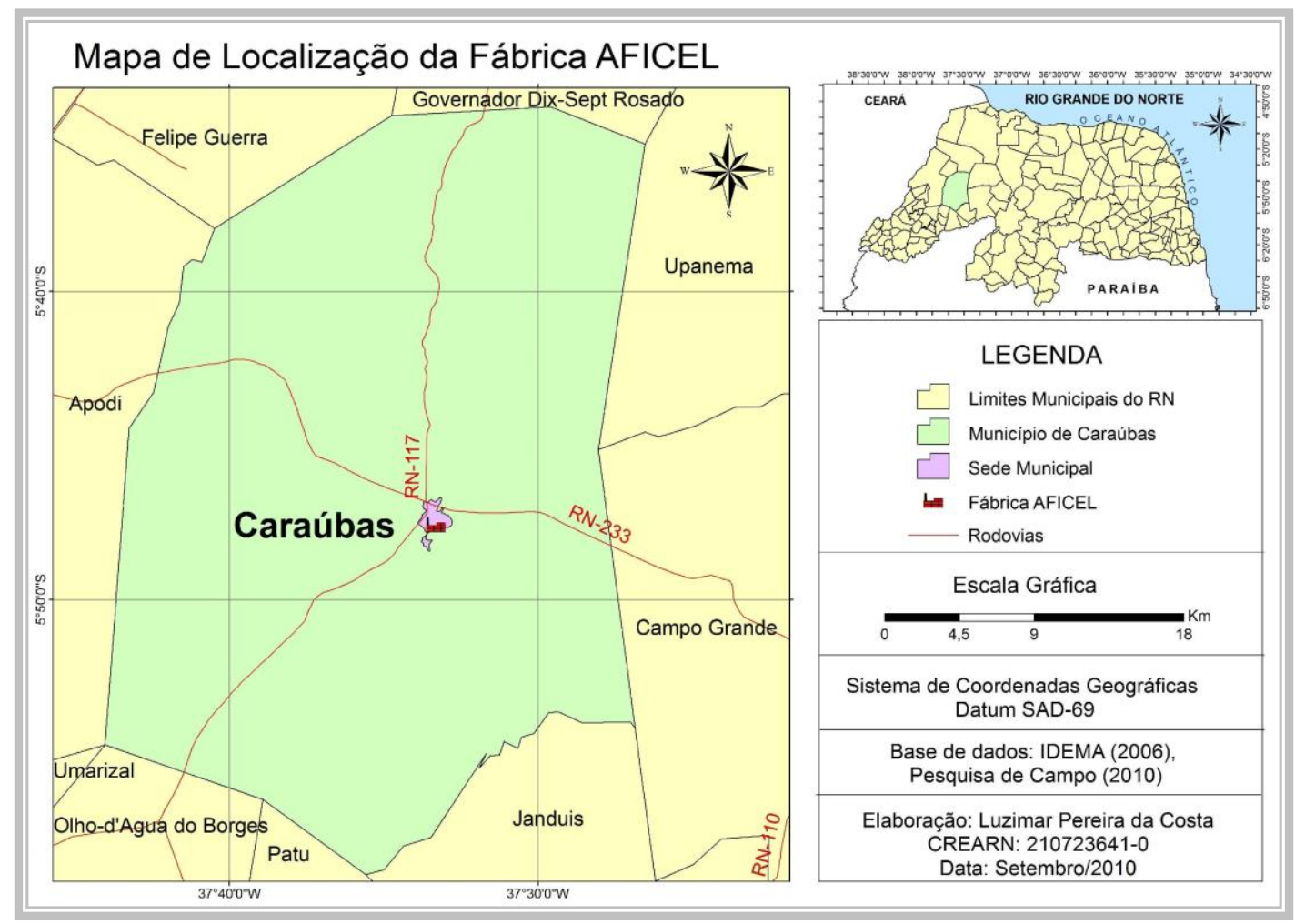

A AFICEL comprava a castanha das comunidades rurais de Caraúbas, principalmente a comunidade de Mirandas e Cachoeira e realizava todas as etapas de beneficiamento da castanha desde o recebimento do produto até a embalagem, exportando, posteriormente para diversos países como Canadá e Estados Unidos. Sobre a instalação da AFICEL em Caraúbas, bem como as etapas de beneficiamento.

A instalação da fábrica de beneficiamento da castanha de caju provocou uma dinâmica socioespacial no município, uma vez que aumentou o número de empregos e serviços na cidade, provocou o aumento do êxodo rural, como também houve uma expansão urbana para as áreas próximas a unidade industrial. 
Ainda sobre a dinâmica socioespacial que a indústria provocou em Caraúbas, em entrevista realizada em junho de 2009 com o atual vice-prefeito do município, Alcivan Viana relata:

Muita gente de outros municípios vinha pra cá e ficavam na porta da AFICEL para vender produtos, roupas, alimentos, objetos para casa dos funcionários da fábrica. Com o tempo, muitas dessas pessoas que antes vendiam na porta abriram seus próprios estabelecimentos comerciais em Caraúbas. Do mesmo jeito, alguns empregados da fábrica, juntaram o salário que recebiam da AFICEL e também abriram pequenos comércios na cidade, ou seja, houve um aumento no número de lojas em Caraúbas na época da instalação da fábrica. (Informação verbal)

Ao buscarmos dados a respeito da produção de castanha de caju nos Censos Agropecuários de 1970, 1980 e 1985, verificamos que apenas nesse último censo (1985) traz informações a respeito da quantidade de amêndoa produzida pelo município que foi de 283 toneladas. A partir daí podemos aferir que a instalação da fábrica de beneficiamento da castanha de caju promoveu uma maior produção da amêndoa por parte dos agricultores, uma vez que não há dados sobre a produção nos censos agropecuários anteriores.

Em 1993, a AFICEL encerra suas atividades no município de Caraúbas, transferindose para o município de Mossoró. Sobre esse fato os administradores nos informaram que a saída da fábrica foi devido a fatores estruturantes. Em Mossoró foi construída uma fábrica muito maior com capacidade de produzir mais e com melhor qualidade. Entretanto, alguns moradores nos informaram que isso não es tá totalmente correto, pois segundo eles, a fábrica deixou de funcionar em Caraúbas por questões políticas, uma vez que os empresários do estabelecimento concorreram a cargos políticos no município, mas foram derrotados.

Caraúbas sente bastante os efeitos da retirada da fábrica em seu município. $O$ índice de desemprego aumentou consideravelmente, as atividades econômicas ficaram concentradas somente na agropecuária, no setor de serviços, nos empregos públicos e nas aposentadorias. Como também vários estabelecimentos comerciais foram fechados.

Com a saída da fábrica, as comunidades rurais que abasteciam a AFICEL também sofreram impactos. Recorrendo aos dados fornecidos pelo IBGE, verificamos que houve declínio na área colhida de castanha de caju no município, pois no ano de 1990 a 1992, auge da produção de castanha de caju, a área colhida em Caraúbas foi de 5.500 hectares, após o fechamento da fábrica essa área passou a diminuir. Em 1994, um ano após a transferência da fábrica, a área colhida foi de 4.400 hectares e com uma produção de 1.144 toneladas, sendo que esses valores foram diminuindo até alcançar o ano 2000. A partir do fechamento da fábrica, os agricultores que antes forneciam a castanha a AFICEL, passaram a fornecer para cidades que possuía minifábricas de beneficiamento da castanha como Apodi e Portalegre.

Em 2004, em parceria com o Governo do Estado do Rio Grande do Norte, a Prefeitura Municipal de Caraúbas e com a AFICEL, a fábrica volta a funcionar, mas em forma de cooperativa, utilizando a infra-estrutura deixada por esse empreendimento. Tal empreitada empregava 180 pessoas do município, em especial do bairro Leandro Bezerra (bairro em que está localizada a fábrica). É a partir desse ano que a área plantada, como a área colhida e a quantidade de produção de castanha aumenta no município. 
A cooperativa funcionou durante cinco anos, de 2004 a abril de 2009, quando a AFICEL retomou suas atividades em Caraúbas. Ao indagarmos sobre o motivo do retorno da fábrica para a cidade, o administrador nos respondeu que foi devido às exigências do mercado que não permitia que a exportação da amêndoa proveniente de cooperativas, pois não existiam leis trabalhistas nestes estabelecimentos. Entretanto, a questão política ressurge. Em 2008, o irmão do dono da AFICEL, Ademar Ferreira ganha as eleições municipais se tornando o prefeito de Caraúbas, e uma das suas primeiras ações foram reativar a AFICEL no município, utilizando o mesmo prédio e infraestrutura da década de 1980.

Desse modo, a AFICEL - Caraúbas entrou em funcionamento em abril de 2009 sendo uma filial de classificação das amêndoas da matriz que se encontra em Mossoró. A fábrica de beneficiamento da castanha de caju continua comprando as castanhas de caju nas comunidades rurais de Caraúbas, principalmente nas comunidades de Mirandas ${ }^{1}$ e Cachoeira.

A filial da AFICEL em Caraúbas conta, atualmente com 300 funcionários, onde $80 \%$ é composto por mulheres, pois de acordo com os administradores, elas são mais sensíveis ao trabalho. Os funcionários têm como serviço fazer a despeliculagem da castanha, s elecionarem e, posteriormente, classificá-las. O regime de trabalho é de segunda a sexta-feira, com uma carga horária de trabalho de 9 horas por dia, para compensar o sábado, dia que a fábrica não funciona. Os funcionários recebem um salário mínimo, entretanto, precisam beneficiar por dia 22 quilos de castanha. Caso não cumpra essa regra, é descontado no salário. Para isso há um fiscal que observa e faz a contagem da castanha no final do expediente por cada funcionário.

A quantidade de castanha beneficiada pela filial da AFICEL varia muito, pois depende da safra, mas a média é de 70 mil quilos beneficiados. É no final do dia que a matriz da fábrica se encarrega de buscar a produção e levá-la para Mossoró, onde a partir daí elas são esterilizadas, passam novamente por um processo de classificação, são embaladas e finalmente são exportadas para diversos países como Estados Unidos e Canadá. De acordo com os administradores da fábrica, $80 \%$ da produção é encaminhada para esses países e o restante segue para São Paulo e Rio de Janeiro.

Nesse contexto, percebemos a importância da fábrica de beneficiamento da castanha de caju a área urbana e rural do município em análise. Dessa maneira, no próximo tópico abordaremos sobre a atual dinâmica socioespacial e econômica de Caraúbas.

\section{A ATUAL DINÂMICA SOCIOESPACIAL E ECONÔMICA DE CARAÚBAS}

A análise sobre o processo de produção do espaço de Caraúbas analisado no início do trabalho, bem como a explanação sobre a atividade da cajucultura, foram importantes para debruçarmos na caracterização socioespacial e econômica do município. Para tanto, recorremos a dados estatísticos disponíveis e as observações sistemáticas realizadas na cidade durante o período de estudo de campo para melhor compreendermos como se configura a atual dinâmica socioeconômica de Caraúbas.

\footnotetext{
${ }^{1}$ A comunidade rural de Mirandas, de acordo com as cartas provinciais, não pertence à Caraúbas e sim ao município de Upanema. Tal erro só foi descoberto no censo demográfico de 2000. Atualmente, há um processo regido por Caraúbas de requerimento da comunida de, uma vez que é esse município que fornece todos os serviços a comunidade. Da mesma forma, a população residente nas Mirandas possui o sentimento de pertencimento a Caraúbas.
} 
De acordo com os dados do Instituto Brasileiro de Geografia e Estatística (IBGE, 2010) o município possui 19.739 habitantes, dos quais, 12.931 habitantes ocupam o espaço urbano e 6.687 a zona rural, como apresentado na tabela 01 que mostra a evolução do total populacional de Caraúbas da década de 1990 a 2010:

Tabela 01 - Evolução do total populacional de Caraúbas/RN

\begin{tabular}{|c|c|c|c|c|}
\hline ANOS & POPULAÇÃO URBANA & POPULAÇÃO RURAL & POPULAÇÃO TOTAL & TAXA DE URBANIZAÇÃO \\
\hline 1970 & 4.554 & 10.991 & 15.545 & $29,3 \%$ \\
\hline 1980 & 7.435 & 11.358 & 18.793 & $39,6 \%$ \\
\hline 1991 & 10.676 & 9.572 & 20.248 & $52,7 \%$ \\
\hline 2000 & 12.304 & 6.506 & 18.810 & $65,4 \%$ \\
\hline 2010 & 13.704 & 5.872 & 19.576 & $70,0 \%$ \\
\hline
\end{tabular}

Fonte: IBGE. Dados demográficos de 1970, 1980, 1991, 2000 e 20010.

Ao analisarmos a tabela 01 percebemos que houve uma diminuição populacional do município no período de 1991 onde se tem 20.248 habitantes em relação a 2000, cujo total passou a ser de 18.810 habitantes. Essa mudança não se deve a diminuição efetiva do total da população de Caraúbas, mas sim a uma mudança na contabilização do censo demográfico realizado pelo IBGE na referida cidade. Após uma revisão feita pelo IBGE acerca da localização de Caraúbas verificou que a comunidade rural Mirandas, na realidade, não pertence à Caraúbas e sim ao município de Upanema - RN. Dessa forma, a população dessa localidade passou a ser incluída no total populacional desse município. Entretanto, há atualmente um processo no sentido de Caraúbas reaver a posse desse território, uma vez que é este município que oferece todos os serviços a comunidade como saúde e educação.

O crescimento da população urbana em Caraúbas, assim como em outras cidades do Brasil, propicia a uma elevação dos níveis de desemprego, subemprego e instalação de pessoas em submoradias, visto que a expansão populacional urbana não é acompanhada pelo aumento da infraestrutura necessária para a população. Acarretando, desse modo, em sérios problemas sociais, como: aumento do desemprego, violência e, principalmente, pobreza por parte da população.

No que diz respeito aos setores essenciais para a população como educação e saúde, Caraúbas segue a tendência nacional, uma vez que esses setores apresentam certa ineficiência não suprindo, assim, as necessidades básicas da população. Em relação à saúde, Caraúbas conta em seu espaço com apenas um hospital, um centro de saúde, três postos médicos distribuídos entre os bairros e uma policlínica particular. Entretanto, tais estabelecimentos hospitalares se restringem a atender casos de pequena complexidade, já os casos de média e alta complexidade são encaminhados para Mossoró ou Natal.

De acordo com o Atlas de Desenvolvimento Humano (2000), quase $60 \%$ da população caraubense se encontra no nível de pobreza, esse fato pode ser claramente compreendido ao percebermos o fraco dinamismo econômico que o município apresenta, pois excetuando os empregos gerados pela prefeitura, pelo Estado e os benefícios pagos pelo INSS, a única fonte de renda do município são as atividades agropecuárias, uma fábrica de beneficiamento da castanha de caju e um incipiente comércio local e os repasses federais advindos do Fundo de Participação dos Municípios - FPM. 
O setor primário de Caraúbas apresenta uma agricultura e pecuária voltada à principalmente à subsistência; o setor secundário restringe unicamente a indústria de beneficiamento da castanha de caju e, por fim, o setor terciário que engloba tanto o comércio como a prestação de serviços é pouco diversificado, mas tem grande relevância, uma vez que a geração de empregos é advinda principalmente por esse setor.

A dinâmica comercial de Caraúbas ocorre por meio do comércio varejista e atacadista e do comércio popular que se concretiza nas feiras semanais as quais ocorrem ainda na maioria das cidades pequenas do Estado. Os estabelecimentos comerciais presentes nesse espaço requerem pouca mão-de-obra, predominando, na maioria das vezes, o caráter familiar em que os funcionários são parentes do proprietário do comércio. Percebe-se que a maior movimentação no comércio de Caraúbas ocorre no período em que são efetuados os pagamentos dos recursos provenientes do funcionalismo público (municipal e estadual), das aposentadorias e nos dias de pagamento da AFICEL.

Outra característica que diz respeito ao comércio de Caraúbas é a sua localização: o centro da cidade, espaço de confluência de atividades rudimentares e artesanais e, ao mesmo tempo de "modernas". Essa área passou a ser considerada como o foco de importantes estabelecimentos comerciais; como também foi o local destinado às relações comerciais e trabalhistas, espaço que se incorporou à vida social da população e se constitui como ponto tradicional de encontro de pessoas e troca de mercadorias.

Toda essa dinâmica socioespacial e econômica de Caraúbas demonstrada até esse momento estão ligadas a atividade da cajucultura. Entretanto, na época do funcionamento da AFICEL enquanto matriz de todo o processo produtivo nas décadas de 1980 e 1990, essa relação era mais intensa; atualmente observamos que essa ligação está mais enfraquecida, mas significativa na dinâmica econômica do município.

Caraúbas conta hoje com 295 estabelecimentos comerciais e muitos proprietários dessas lojas já foram funcionários da AFICEL ou vendiam seus produtos na porta da fábrica. Como ressaltou um comerciante: "eu comecei vendendo na porta da fábrica de caju nos intervalos de trabalho, hoje eu tenho essa loja, passei um bom tempo vendendo lá, depois comprei uma casa pequena, coloquei a loja e fui aumentando aos poucos, hoje eu tô assim" (Informação verbal).

Da mesma forma, quando a safra de castanha de caju é satisfatória, é sentida no comércio local, uma vez que os produtores de caju saem da zona rural em direção a cidade em busca de produtos e serviços que atenda as suas necessidades e da sua família. Ainda nesse contexto, na época de boas safras, a feira livre realizada uma vez por semana passa a ter mais bancas de vendas e estendem o seu horário de funcionamento.

Outras características da produção de castanha de caju e a dinâmica socioespacial de Caraúbas diz respeito à expansão urbana da cidade. As pessoas que vinham do campo, como não tinha onde fixarem residência acabava se instalando nos bairros periféricos da cidade, principalmente no bairro Leandro Maltez, onde se localiza a fábrica, ocorrendo assim uma expansão urbana. Expansão que até hoje não é acompanhada de melhorias de infraestrutura de serviços básicos a população.

A produção de castanha de caju em Caraúbas permite que a cidade mantenha uma relação forte com o campo, pois a matéria-prima é produzida no espaço rural e é beneficiada na zona 
urbana. Desse modo, devemos considerar esses dois espaços em uma visão dialética, com uma extrema relação de reciprocidade.

Em suma, todos esses tópicos levantados nessa etapa do trabalho: a questão do funcionamento do comercio caraubense, do êxodo rural, da expansão urbana, da influência do toque na população e a relação entre o campo e a cidade, nos permite afirmar que a dinâmica socioespacial e econômica do município de Caraúbas está intimamente ligada à produção de castanha de caju.

\section{CONSIDERAÇÕES FINAIS}

Durante todo o desenvolvimento desse trabalho buscamos compreender a dinâmica socioespacial de Caraúbas motivado pela atividade da cajucultura. Foi observado que após a instalação da AFICEL, Caraúbas passa a viver uma nova dinâmica socioespacial, com o aumento no número de empregos na cidade, bem como surgem novos empreendimentos comerciais e ocorre uma expansão urbana da cidade para o bairro em que a fábrica está instalada. Da mesma forma, é no período da instalação da fábrica (década de 1980) que há uma transformação no perfil urbano de Caraúbas, uma vez que o município passa a ter o aumento total de população residente na cidade comparado a população rural.

Quando a safra da castanha de cajue satisfatória é refletida no comércio local, uma vez que os produtores de caju saem da zona rural em direção a cidade em busca de produtos que atenda as suas necessidades e da sua família. Ainda nesse sentido, na época de boas safras, a feira livre realizada uma vez por semana passa a ter mais bancas de vendas e estendem o seu horário de funcionamento. Dessa forma, percebemos a forte ligação que existe entre a cajucultura e a dinâmica socioespacial do município em estudo.

Concluí-se com o desenvolvimento do artigo, que a produção de castanha de caju se configura como sendo uma das principais atividades econômicas de Caraúbas e interferindo diretamente na dinâmica socioespacial do município.

\section{REFERÊNCIAS}

1. ANDRADE, Manuel Correia de. 0 processo de ocupação do espaço regional do Nordeste. 2. ed. Recife: SUDENE, 1979.

2. . A produção do espaço norte-rio-grandense. Natal: Universitária, 1981.

3. BRITO, Raimundo Soares de. Caraúbas Centenária: 1858 - 1958. Mossoró: Coleção Mossoroense, 1958.

4. CARLOS, Ana Fani A. A (re) produção do espaço urbano. São Paulo: EDUSP, 1994.

5. Espaço-tempo na metrópole: a fragmentação da vida cotidiana, São Paulo: Contexto, 2001.

6. Uma leitura sobre a cidade. Cidades, Presidente Prudente, v. 1, n.1, p. 11-30, jan./dez. 2004.

7. FEliPe, J. L. A.; CARVAlHo, E. A.; ROCHA, A. P. B.. Atlas Rio Grande do Norte: Espaço GeoHistórico e Cultural. João Pessoa: GRAFSET, 2002. 
8. Elementos de Geografia do Rio Grande do Norte. Natal: Universitária, 1988

9. FURTADO, Edna Maria. A Cultura do Caju e as Mudanças no Espaço Rural do Município de Lagoa Nova - RN..88f. Dissertação (Mestrado em Geografia). Universidade Federal de Sergipe. Aracaju - SE, 1990.

10. GOTTDIENER, Mark. A produção social do espaço. São Paulo: Edusp, 1997.

11. IDEMA. Perfil do seu município. Disponível em: <http://www.rn.gov.br/secretarias/idema/>. Acesso em: 16 de Novembro de 2008.

12. INSTITUTO BRASILEIRO DE GEOGRAFIA E ESTATÍSTICA. Censos demográficos de 1970, 1980, 1991, 2000 e 2010. Disponíveis em: <http://www.sidra.ibge.gov.br>. Acesso em: 25 de julho de 2010.

13. Censos Agropecuários de 1970, 1980, 1985, 1996 e 2006. Disponíveis em <http://www.biblioteca.ibge.gov.br> Acesso em: 25 de julho de 2010.

14. Levantamento Sistemático da Produção Agrícola Municipal de 1990 a 2009. Disponível em <http://www.sidra.ibge.gov.br>. Acesso em: 25 de julho de 2010.

15. LEFEBVRE, Henry. O direito a cidade. Tradução Rubens Eduardo Frias. São Paulo: Morais, 1991. 16. Henry. A produção do espaço. Mimeog. (capítulos 1, 2 e 6). Belo Horizonte: ICGUFMG, 2006.

17. LEITE, L.A. de S. A agroindústria do caju no Brasil: políticas públicas e transformações econômicas. Fortaleza: EMBRAPA - CNPAT, 1994.

18. OlIVEIRA, Agostinho Gomes de. História do município de Caraúbas: Fundação, desenvolvimento e atualidade. Caraúbas: Coleção Caraubense, 2001.

19. PESSOA, Jomara Dantas. As Pequenas cidades norte-riograndenses: Pensando a Geografia do Presente da cidade de Caraúbas - RN. 2009. 78F. Monografia (Especialização) - Universidade do Estado do Rio Grande do Norte, Mossoró - RN.

20. PNUD; IPEA; FUNDAÇÃO JOÃO PINHEIRO. Atlas do desenvolvimento humano no Brasil: 2003. Software. Disponível em: <www.unpdp.org.br>.

21. SANTOS, Milton. Espaço e sociedade: ensaios. Petrópolis: Vozes, 1979

22. A natureza do espaço: técnica e tempo: razão e emoção. 3.ed. São Paulo: Hucitec, 1999.

23. SOJA, Edward W. Geografias pós-modernas: a reafirmação do espaço na teoria social. Rio de Janeiro: Jorge Zahar, 1993. 